\title{
Skull fracture as a risk factor of intracranial complications in minor head injuries: a prospective CT study in a series of 98 adult patients
}

\author{
FRANCO SERVADEI,* GABRIELE CIUCCI, $\dagger$ FRANCESCO PAGANO, \\ GIAN GIUSEPPE REBUCCI, $\dagger$ MICHELE ARIANO $\ddagger$ GIANCARLO PIAZZA,* \\ GIULIO GAIST*
}

From the Division of Neurosurgery, Ospedale Bellaria, Bologna, ${ }^{*}$ and the Division of Neurology, $\dagger$ and Service of Radiology, $\ddagger$ Ospedale Santa Maria delle Croci, Ravenna, Italy

SUMMARY Ninety eight patients admitted to hospital after a minor head injury were studied by CT. Forty seven patients had a skull fracture and 51 did not. Significantly more intracranial lesions were found in those with a fracture $(16)$ that those without $(3)(\mathrm{p}<0.01)$. Nine of the patients with a skull fracture and positive CT were transferred to a neurosurgical department, where six underwent operation. Operation was not required in patients without a skull fracture. Head injured patients with a skull fracture should undergo CT scanning to enable early detection of an intracranial haematoma.

Many neurosurgeons believe $\mathrm{e}^{1-7}$ that the finding of a skull fracture in a patient with a minor head injury indicates an increased risk of an intracranial haematoma. Radiologists ${ }^{8-13}$ have an opposing viewpoint and consider that the use of skull radiographs in all cases of head injury is exceedingly costly and of limited utility. The objective of the present study was to compare two groups of patients admitted to hospital after a minor head injury; the group were distinguished only by the presence or absence of a fracture on plain radiograph of the skull; all patients were examined prospectively by $\mathrm{CT}$.

\section{Methods}

The study was conducted in the municipal hospital of Ravenna; this does not have a neurosurgical unit but has a CT scanner (GE model 8800) in its radiology department. The patients studied had been selected for admission according to criteria used widely in Italian hospitals. ${ }^{14}$ They had a history of a recent head injury and a Glasgow Coma Score ${ }^{15}$ of 14 or 15 at the time of examination in the casualty department.

Address for reprint requests: Dr F Servadei, Division of Neurosurgery, Ospedale Bellaria, Via Altura, 40139 Bologna, Italy.

Received 6 March 1987 and in revised form 4 June 1987. Accepted 3 September 1987
Children younger than 14 years were not included. Data on such patients who had a skull fracture were collected from January 1985 to June 1986; a comparable number whose skull radiographs did not show fracture were collected in June and July 1985. CT scanning was carried out after admission to hospital, in all except two cases within 4 hours of injury.

\section{Results}

Forty seven patients had a linear skull fracture, and 51 patients had no skull fracture. The two groups had similar ages (respectively 38.7 years mean, range 15 to

Table CT scans vs clinical features in patients with a linear skull fracture

\begin{tabular}{|c|c|c|c|}
\hline & \multicolumn{3}{|l|}{$C T$} \\
\hline & $\begin{array}{l}\text { "Surgical" } \\
\text { lesions }\end{array}$ & $\begin{array}{l}\text { "Nonsurgical" } \\
\text { lesions }\end{array}$ & Negative \\
\hline \multicolumn{4}{|l|}{ Loss of consciousness } \\
\hline absent & 1 & 1 & 3 \\
\hline less than $10 \mathrm{~min}$ & 4 & 4 & 18 \\
\hline more than $10 \mathrm{~min}$ & 5 & 2 & 9 \\
\hline \multicolumn{4}{|c|}{ Headache, Vomiting, Vertigo, etc } \\
\hline present & 7 & 1 & 14 \\
\hline absent & 3 & 6 & 16 \\
\hline \multicolumn{4}{|l|}{ GCS score } \\
\hline 14 & 5 & 5 & 6 \\
\hline 15 & 5 & 2 & 24 \\
\hline
\end{tabular}


80 years and 35.7 years mean, range 15 to 83 years); similar numbers had an initial loss of consciousness respectively 43 and 45 patients and continuing impairment of consciousness (Glasgow Coma Score = 14) when admitted (16 and 21 patients respectively).

\section{Number and types of lesions on CT}

Sixteen patients with a skull fracture had an abnormal CT scan but only three of those that had no skull fracture. This difference was significant $(p=0 \cdot 01)$.

Eight patients with a fracture had an extradural haematoma, ranging from 4 to $14 \mathrm{~mm}$ thick; four had a haemorrhagic contusion, from 2 to $3.5 \mathrm{~cm}$ wide; one had a $1 \mathrm{~cm}$ deep subdural haematoma, and three had intracranial air. Two patients without a fracture had a contusion, 1.5 and $2 \mathrm{~cm}$ wide, and one had post traumatic subarachnoid haemorrhage; none of these required surgery:

Patients with a fracture had significantly more lesions, $\left(\chi^{2}=7.02 ; \mathrm{p}=0.01\right)$ and also more lesions considered to be "surgical" $\left(\chi^{2}=6.98 ; p=0 \cdot 01\right)$.

Prolonged loss of consciousness, symptoms of headache, vomiting or vertigo, and mild impairment of consciousness (GCS 14) were more frequent in patients with "surgical" lesions, but the difference was not statistically significant (table).

Management Five patients with a skull fracture underwent craniotomy, two for an extradural haematoma and three for "lacerations" associated with mass effect; another later underwent burr hole evacuation for a subacute subdural haematoma. Repeat studies on the remaining patients with an abnormal CT scan showed disappearance of the lesion within 2 months. All patients had made a good outcome ${ }^{16}$ at 6 months.

\section{Discussion}

The controversy about the importance of a fracture as a risk factor in mild head injuries reflects the opposing viewpoints of radiologists and neurosurgeons. The former are concerned with the large scale use of emergency skull films in relation to the small number of patients who prove to need referral to neurosurgeons. The latter regard skull films as valuable in triage. Neither standpoint has provided unequivocal findings or practical guidelines for physicians in emergency circumstances. ${ }^{17}$

Our findings support the view ${ }^{5}$ that the presence of a fracture is a more important indication of the risk of complications that a transient loss of consciousness. ${ }^{18}$ The risk of an intracranial haematoma in an alert patient with a skull fracture was estimated by Mendelow et al ${ }^{5}$ to be $3 \%$. Our series has shown a similar incidence of lesion producing clinical deterioration ( 2 out of $47: 4 \cdot 2 \%$ ). A higher yield was found when all lesions considered by the referring clinicians to be potentially of "surgical significance" $(19 \%)$ or when all CT abnormalities (34\%) were included.

It is difficult to compare other reports with the present series. Widely varying proportions of head injured patients are reported to have a skull fracture. The inclusion of children complicates analysis; they more often have a haematoma in the absence of a fracture and were therefore excluded from our study.

The aim in care for minor head injuries should no longer be to detect and to treat patients who deteriorate neurologically after a period of relative alertness. ${ }^{6}$ Instead, patients should be identified while asymptomatic in order to plan more effective treatment. Two patients in this study deteriorated during transfer; if their CT scan had not been performed early, deterioration would have occurred in the referring hospital: Early detection of an intracranial haematoma, leads to improved results and to the possibility of minimal mortality and morbidity. ${ }^{19}$

The increased provision of CT has made it feasible to consider CT of all minor head injuries with a skull fracture. In the region covered by our neurosurgical unit (population approximately 2,000,000) there are now seven scanners available for investigation of head injuries on a 24 hour basis. The incidence of head injuries complicated by a skull fracture is estimated to be 35 per 100,000 population per year in our area. ${ }^{20} \mathrm{~A}$ similar figure is reported from the USA, 45 per 100,000 per year. ${ }^{21}$ The performance of CT on adults wth a minor head injury with a skull fracture would result in an extra yearly workload of 50 to 60 patients per scanner in our area. We believe that this is justified in a system based upon national health care, such as in Italy, in view of the benefits that result.

\section{References}

1 Miller JD, Jones PA. The work of a regional head injury service Lancet 1985;i:1141-4.

2 Miller JD. Minor, moderate and severe head injury. Neurosurg Rev 1986;9:135-9.

3 Fisher RP, Carlson J, Perry JF. Postconcussive hospital observation of alert patient in a primary trauma center. Trauma 1981;21:920-4.

4 Mendelow AD, Campbell DA, Jeffrey RR, et al. Admission after mild head injury: benefits and costs. Br Med J 1982; 285: $1530-2$.

5 Mendelow AD, Teasdale G, Jennett B, Bryden J, Hesset C, Murray G. Risks of intracranial haematoma in head injured adults. Br Med J 1983;287:1173-6.

6 Dacey RG, Wayne AM, Rimel RW, Wim R, Jane JA. Neurosurgical complication after apparently minor head injury: assessment of risk in a series of 610 patients. $J$ Neurosurg 1986;65:203-10.

7 Jennett B. Skull $\mathrm{x}$-rays after recent head injury. Clin Radiol 1980;31:463-9.

8 Cooper PR, Ho V. Role of emergency skull x-ray films in the evaluation of head injured patient. A retrospective study. 
Neurosurgery 1983;13:136-40.

9 Royal College of Radiologists: costs and benefits of skull radiography for head injury. Lancet 1981;ii:791-5.

10 Thornbury JR, Campbell JA, Masters SJ, Fryback DG. Skull fracture and low risk of intracranial sequelae in minor head trauma. $A J R$ 1984;143:661-4

11 Boulis ZF, Dick R. Head injury in children. Aetiology, symptoms, physical findings and $\mathrm{x}$-ray wastage. $\mathrm{Br} \mathrm{J}$ Radiol 1978;51:851-4.

12 Masters SJ. Evaluation of head trauma: efficacy of skull films. AJR 1980;135:539-47.

13 Gibson TC. Skull x-rays in minor head injury. Scott Med J 1983;28:132-7.

14 Servadei F, Bastanelli S, Naccarato S, et al. Epidemiology and sequelae of head injury in San Marino Republic. J Neurosurg Sci 1985;4:297-303.
15 Teasdale G, Jennett B. Assessment of coma and impaired consciousness: a practical scale. Lancet 1974;ii:81-4.

16 Jennett B, Bond M. Assessment of outcome after severe brain damage: practical scale. Lancet 1977;i:873-81.

17 Hoff JT. Emergency skull x-ray films (Comment). Neurosurgery 1983;13:139.

18 Briggs M, Clarke $\mathrm{P}$, Crockard, et al. Guidelines for initial management after head injury in adults. Br Med $J$ 1984;288:983-5.

19 Bricolo P, Pasut LM. Extradural hematoma: toward zero mortality. Neurosurgery 1984;14:8-12.

20 Ciucci G, Servadei F, Rebucci GG, et al. (Head injuries in Ravenna: prospective study of hospitalized patients). Engl Abst Riv Pat Nerv Ment 1984;105:153-66.

21 Nelson EL, Melton JL, Annegers JF, Laws ER, Offord KP. Incidence of skull fracture in Olmstead County, Minnesota. Neurosurgery 1984;15:318-24.

\section{Parinaud's syndrome}

\section{A: Essential Paralysis of Convergence}

"... (a) Paralysis of the movement of convergence is indicated by two principal symptoms: the objectively appreciable defect of convergence and a peculiar diplopia... The diplopia appears in the median plane at a variable distance from the subject; it is crossed, and there is moderate separation of the images which persist without notable modification in all directions of looking... The images not infrequently become fused at four or five meters from the patient, a distance at which but little convergence is exercised, but cases do occur in which the diplopia persists at all ranges; ... (b) Accommodation is involved... in various ways. In certain cases there is absolute paralysis in both eyes; in others there is more or less notable reduction of its amplitude: whilst in a third class the accommodation is normal. (c) If in this form of paralysis there be no paralytic mydriasis, the pupillary reflexes are nevertheless modified... The reflex is abolished for convergence and retained for light, thus constituting a modification exactly inverse to that pointed out by Argyll Robertson as occurring in tabes".

\section{B: Combined Paralysis of Convergence}

"... The defect of convergence is accompanied by paralysis of elevation, and of depression in both eyes, with retention of lateral movements. This ... appears to be very rare in its complete form".

Parinaud H. Paralysis of the movement of convergence of the eyes. Brain 1886;9:330-41.
From the Tadhkirat of Ali ibn Isa of Baghdad (c. 940-1010 AD) ${ }^{1}$ an ancient description of what may be temporal arteritis.

"On Excision of Arteries and their Cauterization ... one treats not only migraine and headache in those patients that are subject to chronic eye disease but also acute, sharp, catarrhal affections, including those showing heat in and inflammation of the temporal muscles. These diseased conditions may terminate in loss of eyesight; frequently they are attended by a considerable degree of chemosis."

\section{Reference}

RT ROSS, MD

1 Memorandum Book of a Tenth-Century Oculist. A translation of the Tadhkirat of Ali ibn Isa (c. 940-1010 Ad)-translated by Casey A Wood. Chicago: Northwestern University Press, 1936:225. 